\title{
Valuable product production from wood mill effluents
}

\author{
T. Mato, M. Ben, C. Kennes and M. C. Veiga
}

Water Science \& Technology, Vol 62 No 10 pp 2294-2300 , IWA Publishing 2010

doi:10.2166/wst.2010.949

\begin{abstract}
Fibreboard production is one of the most important industrial activities in Galicia (Spain). Great amounts of wastewater are generated, with properties depending on the type of wood, treatment process, final product and water reusing, among others. These effluents are characterized by a high chemical oxygen demand (COD), low $\mathrm{pH}$ and nutrients limitation. Aerobic and anaerobic processes have been used for their treatment. Presently, bioplastics production (mainly polyhydroxyalkanoates or PHA) from wastewaters with mixed cultures is being studied. Substrate requirements for these processes are a high organic matter content and low nutrient concentration. Therefore, wood mill effluents could be a suitable feedstock. PHA production from wastewaters is carried out in three steps. First, complex organic matter is converted into volatile fatty acids (VFA) through acidogenic fermentation. Then, VFA are used as substrate in an aerobic sequencing batch reactor (SBR), in which the enrichement of PHA producing bacteria from a mixed culture is favoured. Finally, the sludge from the SBR is fed with a pulse containing high VFA concentrations, resulting in PHA accumulation inside the cells. In this work, the possibility of applying this process to wood mill effluents is proposed. An acidification percentage of $37 \%$ and a storage yield ( $\mathrm{Y}_{\mathrm{STO}}$ ) of $0.23 \mathrm{Cmmol} / \mathrm{Cmmol}$ were obtained.
\end{abstract}

\section{Keywords}

Acidogenic fermentation; bioplastics; PHA; SBR; VFA; wood mill effluent 


\section{Introduction}

Fibreboard production is one of the most important industrial activities in Galicia (Spain), processing two million $\mathrm{m}^{3} /$ year of wood. In the production process of medium density fibreboard (MDF) great amounts of wastewater are generated, producing a negative environ- mental impact. The properties of these wastewaters depend on the type of wood, treatment process, final product and water reuse, among others. In general, these effluents are characterized by a high COD content, low $\mathrm{pH}$ values and nutrients limitation.

Anaerobic digestion is one of the most suitable processes to treat them. It works without oxygen supply, the amount of sludge generated is lower than in aerobic processes and it produces biogas, which can be used as fuel. Anaerobic systems used until now include the upflow anaerobic sludge blanket (UASB) reactor, upflow sludge bed filter (USBF), anaerobic filter (AF), sequencing batch reactor (SBR) and fed batch reactor (FBR) (Vidal \& Diez 2005). These systems achieve COD removals in the range of 50 90\%. High COD removal efficiencies can also be attained with aerobic processes, up to $80 \%$. Other biological processes based on algae and fungi or physical-chemical treatments like ozonation, photocatalysis, electrochemical processes and coagulation-floculation can also be used (Amat et al. 2005).

Conventional treatments consist only in contaminants removal, but nowadays there is a trend to produce valuable products from wastes. In recent years, bioplastics production (mainly PHA) from wastewaters and mixed cultures has been studied. PHA are polyesters of various hydroxyalkanoates (HA) which have plastic properties.

They are produced by bacteria as carbon and energy reserves. Therefore, they are completely degraded by the microorganism. Although PHA are known since 1888 and industrially produced since the 1970s conventional plastics have so far not been substituted by bioplastics. Until now, the main obstacle to the replacement of conventional plastics by PHA is the great cost difference (9 e/Kg for PHA against $1 \mathrm{e} / \mathrm{Kg}$ for conventional plastics). PHA price is highly dependent on substrate costs, which represent about $40 \%$ of the total production cost (Lee 1996). An alternative to reduce PHA prices would be to use mixed cultures and cheap substrates such as waste. Substrate requirements for this kind of processes are a high organic matter content and low nutrient concentration, so wood mill effluents could be a suitable feedstock.

PHA production from wastewaters is carried out in a three-stage process. First, complex organic matter present in the wastewater is converted to VFA through acidogenic fermentation. Then, VFA are used as substrate in an aerobic SBR, in which the enrichment of PHA producing bacteria from a mixed culture is favoured. Finally, the sludge from the SBR is fed with a pulse containing high VFA concentrations, resulting in PHA accumulation inside the cells.

Until now, there is scarce literature on this topic using wood mill effluents. Stuthridge et al. (2009) are working on bioplastics (PHA) production from pulp and paper wastestreams. Bengtsson et al. (2008a,b) are studying PHA 
production with different wastewaters, including paper mill effluents. However, paper mill wastewaters contain contaminants proceeding from bleaching processes which are not present in wood mill effluents. Therefore, their characteristics could be different.

In this work, the possibility to apply this process to wood mill effluents is proposed. This would allow converting wood wastes into valuable products, such as bioplastics, managing at the same time to reduce aerobic sludge production.

\section{Materials and methods}

\section{Experimental set-up}

\section{Acidogenic fermentation}

Acidogenic fermentation was carried out in a continuous stirred tank reactor (CSTR) with a useful volume of $1.6 \mathrm{~L}$ (Figure 1) and a settler of $0.8 \mathrm{~L}$. It was inoculated with biomass from the anaerobic reactor of a brewery industry wastewater treatment plant in Galicia (Spain). The concentration of volatile suspended solids (VSS) was $4 \mathrm{~g} / \mathrm{L}$ and the operational temperature was $30^{\circ} \mathrm{C}$. The reactor was operated at a hydraulic retention time (HRT) of $1 \mathrm{~d}$ and an average organic loading rate (OLR) of $6.5 \mathrm{~g} \mathrm{COD} / \mathrm{L} \mathrm{d}$. $\mathrm{pH}$ was kept constant at 5.5 by addition of a $2 \mathrm{M} \mathrm{NaOH}$ solution.

\section{Aerobic biomass enrichment}

Aerobic activated sludge was enriched in a 1L-SBR. The SBR was operated under aerobic dynamic feeding (ADF) conditions, alternating short and long periods of excess and absence of substrate, respectively. The SBR cycle lasted 12 hours divided in three steps: aerobic reaction $(10.8 \mathrm{~h})$, settling $(1 \mathrm{~h})$ and effluent withdrawal $(0.2 \mathrm{~h})$. The medium discarded was replaced with fresh medium during the first two minutes of the aerobic step. The HRT was $1 \mathrm{~d}$ and the solid retention time (SRT) was 7 d. Air was supplied at a flow rate of $1 \mathrm{vvm}$. $\mathrm{pH}$ and temperature in the reactor were not controlled, but they were monitored. The reactor was fed with fermented brewery wastewater supplemented with ammonia to obtain a concentration of $1.4 \mathrm{Nmmol} / \mathrm{L}$ at the beginning of the cycle.

\section{Aerobic batch assay}

An aerobic batch assay was undertaken in a $0.6 \mathrm{~L}$ glass vessel connected to a respirometer, where the oxygen uptake rate (OUR) was measured. The air flow rate was controlled by a manometer and kept constant at 1 vvm. $\mathrm{pH}$ and temperature were not controlled. The reactor was inoculated with biomass collected from the SBR described previously. Initial biomass concentration in the batch reactor was $2.0 \mathrm{~g} / \mathrm{L}$. Fermented wood mill effluent containing $52.6 \mathrm{Cmmol} \mathrm{VFA} / \mathrm{L}$ was used as substrate. VFA composition in the substrate was: 62\% acetate and $32 \%$ propionate. Butyric and ethanol were present in negligible concentrations. Ammonia 
was not added as it was present in the fermented wood mill effluent at high concentration (2.6 Nmmol/L).

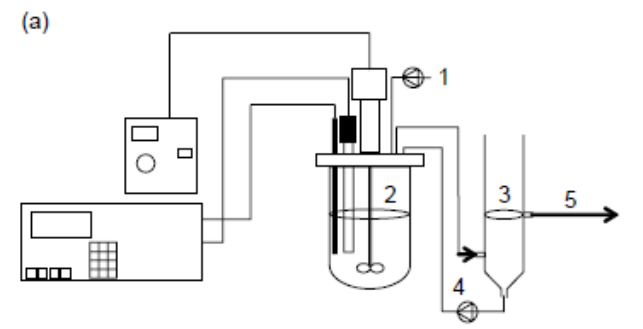

(b)

Figure 1 | (a) Scheme of the acidogenic reactor. 1. Feed; 2. Stirred tank; 3. Settler, 4. Recirculation line; 5. Effluent. (b) Scheme of the sequencing batch reactor (SBR). 1. Feed; 2. Reaction vessel; 3. Respirometer, 4. Effluent.

\section{Influent wastewater}

The acidogenic reactor was fed with water collected from a wood industry producing MDF. This mill uses pine and black poplar as raw material for its process, with a proportion of $80 \%$ and $20 \%$, respectively. The type of wood used in the fibreboard production process affects the composition of the final effluent and thus, the biodegradability of the wastewater. The VFA proportions obtained at the end of the fermentation could depend on the type of wood.

Wastewater treatment plant of thismill consists of two units: flotation, anthracite filter, cartridge filters and reverse osmosis. During two months, samples have been collected weekly in different points of the treatment plant: raw wastewater, flotation outlet and reverse osmosis outlet (final effluent). General parameters of wastewater characterization were measured in each point, giving the average results shown in Table 1.

\begin{tabular}{|l|l|l|l|l|}
\hline Parameter & Units & $\mathbf{1}$ & $\mathbf{2}$ & $\mathbf{3}$ \\
\hline $\mathrm{COD}_{\mathrm{T}}$ & $\mathrm{mg} / \mathrm{L}$ & 42,582 & 11,110 & 1,193 \\
\hline $\mathrm{COD}_{\mathrm{S}}$ & $\mathrm{mg} / \mathrm{L}$ & 14,767 & 10,540 & 1,132 \\
\hline $\mathrm{COD}_{\mathrm{S}} / \mathrm{COD}_{\mathrm{T}}$ & & 0.37 & 0.96 & 0.96 \\
\hline $\mathrm{BOD}_{5}$ & $\mathrm{mg} / \mathrm{L}$ & 6,422 & 3,922 & 220 \\
\hline $\mathrm{BOD}_{5} / \mathrm{COD}_{\mathrm{T}}$ & & 0.16 & 0.36 & 0.21 \\
\hline TSS & $\mathrm{mg} / \mathrm{L}$ & 13,874 & 60 & 4 \\
\hline $\mathrm{VSS}$ & $\mathrm{mg} / \mathrm{L}$ & 13,491 & 53 & 3 \\
\hline $\mathrm{NH}$ & $\mathrm{mg} / \mathrm{L}$ & 18.2 & 2.3 & 2.7 \\
\hline TKN & $\mathrm{mg} / \mathrm{L}$ & 241 & 109 & 11 \\
\hline pH & & 4.6 & 5.8 & 4.9 \\
\hline Alkalinity & $\mathrm{mg} / \mathrm{L}$ & 170 & 753 & 67 \\
\hline
\end{tabular}

Table 1. Wood mill effluents characterization at different sampling points in the wastewater treatment plant of a MDF mill. Sampling points numbers correspond to: 1 . Raw wastewater; 2 . Flotation outlet; 3 . Reverse osmosis outlet (final effluent) 


\section{Analytical procedures}

Total suspended solids (TSS), VSS, biochemical oxygen demand (BOD) and total Kjeldahl nitrogen (TKN) were measured as described in Standard Methods (APHA - AW- WA - WPCF 1998). Total and soluble chemical oxygen demand (CODT and CODS, respectively) were evaluated by a method consisting in the acid digestion of the sample with dichromate at $150^{\circ} \mathrm{C}$. Ammonium and phosphate concentrations were determined using colorimetric methods.

VFA (acetate, propionate, butyrate, i-valerate and n-valerate) and ethanol concentrations were determined by high performance liquid chromatography (HPLC) using a Hewlett Packard chromatograph equipped with a Supel- cogel C-610 column using a UV detector and a RI detector, respectively. Phosphoric acid $0.1 \%$ was used as mobile phase, with a flow of $0.5 \mathrm{ml} / \mathrm{min}$. The column was kept at $30^{\circ} \mathrm{C}$. The wavelength for detection was set at $210 \mathrm{~nm}$. VFA concentrations were calculated using a calibration curve ranging from 25 to $3,000 \mathrm{mg} / \mathrm{L}$.

PHA were determined by gas chromatography (GC)following the method described by Braunegg et al. (1978), modified by Comeau et al. (1988) and Satoh et al. (1992). The method consists on the rupture of cell membranes and structures. Then, the PHA chains are hydrolysed and the monomers are methylated. The methylated monomers are extracted with chloroform, injecting the organic phase in a liquid-gas chromatograph. A calibration curve with $\mathrm{P}(\mathrm{HB}-\mathrm{HV})$ standard $(88 \% / 12 \%)$ corrected by an internal standard (heptadecane) was used to determinate hydroxy- butyrate (HB) and hydroxyvalerate (HV) concentrations.

\section{Calculations}

\section{Acidogenic fermentation}

The total VFA concentration corresponds to the sum of acetate, propionate, butyrate, i-valerate and n-valerate concentrations. The percentage of organic matter conversion into VFA was calculated as (VFA COD $\mathrm{mg}$ in the effluent/COD $\mathrm{mg}$ in the influent)*100. The acidogenic activity was considered as mg of VFA in the effluent per mg of biomass in the reactor (both in $\mathrm{C} \mathrm{mg}$ ) and per litre.

Aerobic batch assay

Sludge PHA content was determined as a fraction of VSS on a mass basis $(\% \mathrm{PHA}=\mathrm{PHA} * 100 / \mathrm{VSS}$; $\mathrm{PHA}$ and VSS concentration in $\mathrm{g} / \mathrm{L})$. Biomass concentration consisted in the sum of PHA content and active biomass ( $\mathrm{SSV}=\mathrm{PHA}+\mathrm{X}$; where $\mathrm{X}$ represents the active biomass).

Active biomass was calculated considering all ammonia was used only for growth. The PHA concentration corresponds to the sum of HB and HV monomers. PHA production ( $\left.\mathrm{Y}_{\mathrm{STO}}\right)$ on substrate consumed was calculated as the ratio between the overall amount of PHA and the total amount of substrate consumed. The specific HA production (DfHA) was determined by 
substracting the initial specific HA concentration from the final specific HA concentration (Cmmol HA/Cmmol X).

\section{Results}

Biodegradability of and VSS concentrations, reaching 13,874 and 13,491 $\mathrm{mg} / \mathrm{L}$, respectively. $\mathrm{BOD}_{5} / \mathrm{COD}_{\mathrm{T}}$ in this stream has a value of 0.16 , which indicates a low biodegradability. Nevertheless, after flotation, $\mathrm{COD}_{\mathrm{T}}$ is reduced to $11,110 \mathrm{mg} \mathrm{COD} / \mathrm{L}$, solids are almost completely removed, and the wastewater biodegradability increases up to 0.36 . The rest of the CODT and solids are removed by reverse osmosis.

In order to determine if the raw wastewater (stream 1) biodegradability could be improved after filtration, total and soluble $\mathrm{BOD}_{5}$ and $\mathrm{BOD}_{11}$ were determined. Results obtained from these assays (Table 2) show that wastewater biodegradability was enhanced by filtering the sample, and it did also improve with time, since complex organic matter is present in this kind of effluents, which needs a long time to degrade.

Due to its biodegradability, solids content and $\mathrm{COD}_{\mathrm{T}}$ concentration, stream 2 was selected as substrate for fermentation. $\mathrm{COD}_{\mathrm{T}}$ in this stream is still high to obtain important VFA concentrations in the acidogenic fermenta- tion, at the same time that solids content is low and biodegradability high, avoiding operational problems in the acidogenic reactor. Furthermore, this stream was also analysed for total sugars content, showing that a $27 \%$ of $\mathrm{COD}_{\mathrm{T}}$ are sugars, which are a good substrate for VFA production by fermentation.

\section{Acidogenic fermentation}

As stated previously, stream 2 (flotation outlet) was selected as influent wastewater for acidogenic reactor, because of its high biodegradability. Wastewater was diluted $(1 / 2)$ in order to obtain the desired COD at the inlet of the reactor, ranging between 5,000 and 6,100 $\mathrm{mg}$ COD/L. No nutrients were added, since they were present in wastewater at concentrations high enough for biomass growth, ammonia concentration was between 13.5 and $30.0 \mathrm{mg} / \mathrm{L}$. Solution was fed to the reactor with an average OLR of $5600 \mathrm{mg} / \mathrm{L} \mathrm{d}$.

\begin{tabular}{lll} 
Parameter & Units & Value \\
\hline $\mathrm{COD}_{\mathrm{T}}$ & $\mathrm{mg} / \mathrm{L}$ & 56,510 \\
$\mathrm{COD}_{\mathrm{S}}$ & $\mathrm{mg} / \mathrm{L}$ & 15,079 \\
$\mathrm{BOD}_{\mathrm{T} 5}$ & $\mathrm{mg} / \mathrm{L}$ & 12,785 \\
BOD $_{\mathrm{T} 11}$ & $\mathrm{mg} / \mathrm{L}$ & 19,185 \\
$\mathrm{BOD}_{\mathrm{S} 5}$ & $\mathrm{mg} / \mathrm{L}$ & 7,098 \\
$\mathrm{BOD}_{\mathrm{S} 11}$ & $\mathrm{mg} / \mathrm{L}$ & 10,948 \\
BOD $_{\mathrm{T}} / \mathrm{COD}_{\mathrm{T}}$ & & 0.23 \\
BOD $_{\mathrm{T} 11} / \mathrm{COD}_{\mathrm{T}}$ & & 0.34 \\
BOD $_{\mathrm{S} 5} / \mathrm{COD}_{\mathrm{S}}$ & & 0.47 \\
$\mathrm{BOD}_{\mathrm{S} 11} / \mathrm{COD}_{\mathrm{S}}$ & & 0.73
\end{tabular}


As can be seen in Figure 2, the influent COD in the acidogenic reactor was $5.6 \mathrm{~g} \mathrm{COD} / \mathrm{L}$ on average, with a VFA concentration less than $1 \mathrm{~g} \mathrm{COD/L}$. Neither ethanol nor other alcohols were present in the feed. Total sugars accounted for $33 \%$ of influent COD. The value of COD detected in the effluent of the acidogenic reactor was4.5 $\mathrm{g} \mathrm{COD} / \mathrm{L}$, containing a concentration of VFA of2 $\mathrm{g} \mathrm{COD} / \mathrm{L}$. EtOH was also formed, but at concentrations lower than $0.3 \mathrm{~g} \mathrm{COD/L}$. As can be observed, $2.2 \mathrm{~g} \mathrm{COD/L}$.

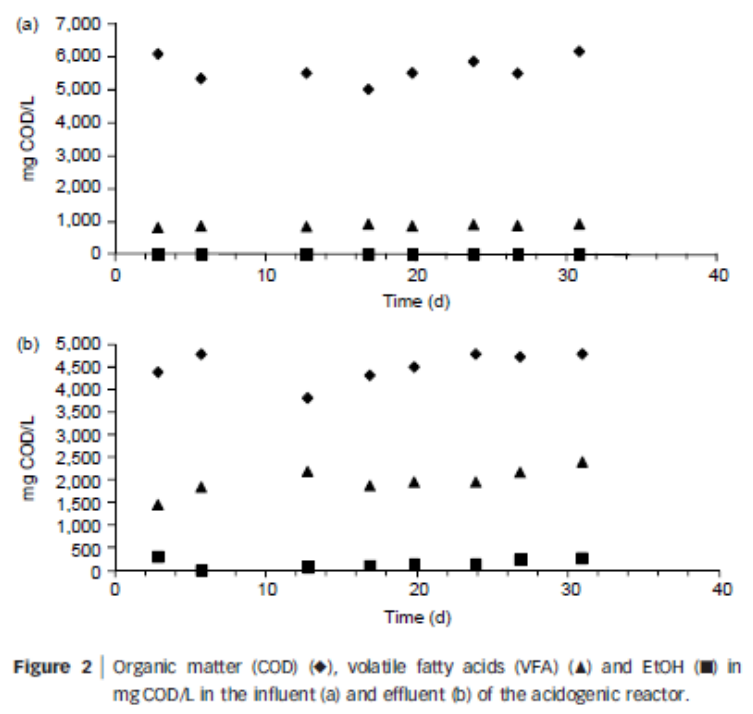

were not degraded, which accounted for a $20 \%$ of the influent COD. This fact indicates that a further optimization of the operational conditions is needed, in order to get a better COD removal.

The acidogenic reactor began to convert organic matter from the influent into VFA immediately after inoculation. Acidification percentage was maintained stable during the reactor operation, with an average value of $37 \%$. The acidogenic activity of the mixed culture was

0.32 VFA Cmg/VSS Cmg L. This low value could be due to the possible presence of inhibitors in wood mill effluents or simply to the nature of organic matter present in this effluent. Increasing the HRT the acidification percentage could be improved, since in BOD assays it was proven that a higher biodegradability was reached at the higher reaction time.

Aerobic batch assay

In order to study the feasibility of using fermented wood mill effluents to obtain PHA, a batch assay was carried out with the acidogenic effluent and sludge enriched in biomass with a high storage capacity. The air flow rate was kept at $1.0 \mathrm{vvm}$. pH and temperature were not controlled during the assay, varying freely. 
The inoculum was taken from an aerobic SBR operated under dynamic conditions and fed with fermented brewery wastewater. The system operated with brewery wastewater was stable over time, obtaining $\mathrm{Y}_{\text {STO }}$ of $0.36 \mathrm{Cmmol} / \mathrm{Cmmol}$ and a HA content of $30-35 \%$ (Figure 3). The acidogenic effluent collected for the assay was characterised by a VFA concentration of $52.6 \mathrm{Cmmol} / \mathrm{L}$ and ammonia concentration of $2.6 \mathrm{Nmmol} / \mathrm{L}$. VFA accounted for most of the COD present in the acidogenic effluent, but $20 \%$ of the initial COD was not degraded.
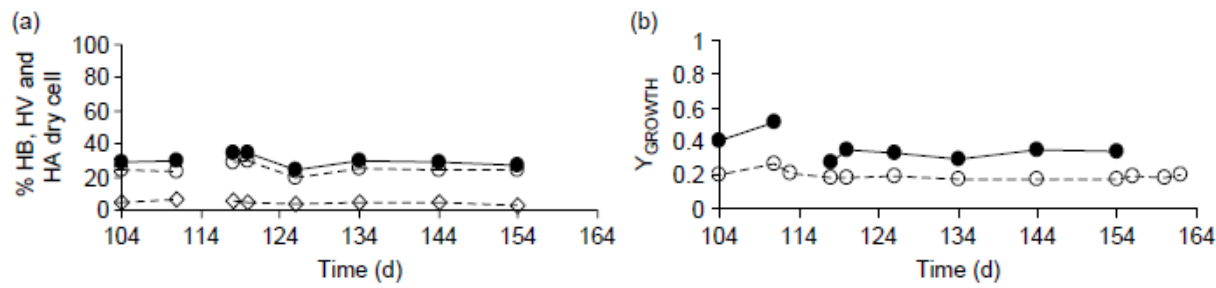

Figure 3 | (a) Hydraxybutyrate $(\mathrm{HB})(\mathrm{O})$, hydroxyvalerate $(\mathrm{HV})(\mathrm{O})$ and hydroxyalkanoate $(\mathrm{HA})(\bullet)$ content in dry cell. (b) Storage yield $\left(\mathrm{Y}_{\mathrm{STO}}\right)(\mathrm{O})$ and storage growth $\mathrm{N}_{\mathrm{CRowm}}$ (•) achieved in SBR fed with brewery wastewater.

Figure 4 shows the concentration profile of VFA consumed during the assay. A 1hour lag phase in substrate concentration profiles was observed which might represent a substrate inhibition. It could be due to the use of sludge acclimated to another wastewater. Brewery wastewater is characterised by a high content of simple organic molecules which are almost totally converted to VFA and gas. Wood mill effluent, at the operational conditions applied during acidogenic fermentation, was not totally converted to VFA, ethanol and gas. Large amounts of complex organic matter remained in the acidogenic effluent, which could make VFA uptake difficult.

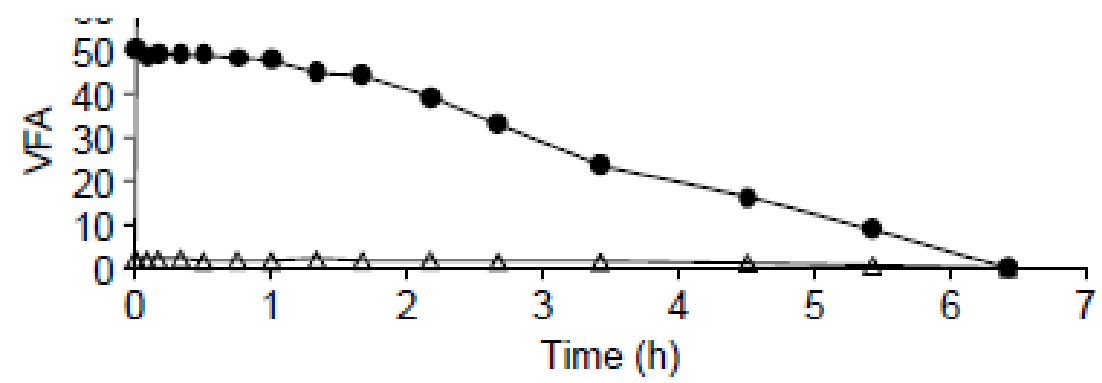

Figure 4 | Concentration profiles of VFA (•) and ethanol ( $\Delta$ ) during the assay.

$\mathrm{Y}_{\text {STO }}$ obtained during the assay was very low $(0.23 \mathrm{Cmmol} / \mathrm{L})$ and similar to the attained $\mathrm{Y}_{\mathrm{GROWTH}}(0.25 \mathrm{Cmmol} / \mathrm{Cmmol})$. HA content in dry cell was $25 \%$ (Figure 5). This could be a consequence of the high ammonia content present in the substrate $(2.6 \mathrm{Nmmol} / \mathrm{L})$. High ammonia concentrations are known to enhance the growth process against the storage process. Serafim et al. (2004) observed an increase in HA content (from 25.4 to 38.6\%) and an increase in $\mathrm{Y}_{\mathrm{STO}}$ (from 0.37 to $0.72 \mathrm{Cmmol} / \mathrm{Cmmol}$ ) when the ammonia concentration decreased from 2.8 to $0.7 \mathrm{Nmmol} / \mathrm{L}$. Albuquerque et al. (2007) developed batch assays with different acidogenic effluents from molasses fermented under different conditions of $\mathrm{pH}$ and 
$\mathrm{C} / \mathrm{N}$ ratio. They observed a $\mathrm{Y}_{\text {STO }}$ increase (from 0.4 to0.65 $\mathrm{Cmmol} / \mathrm{Cmmol}$ ) and a YGROWTH decrease (from 0.3 to $0.004 \mathrm{Cmmol} / \mathrm{Cmmol}$ ) with the ammonia reduction from $7-8.3$ to $0.1 \mathrm{Nmmol} / \mathrm{L}$.

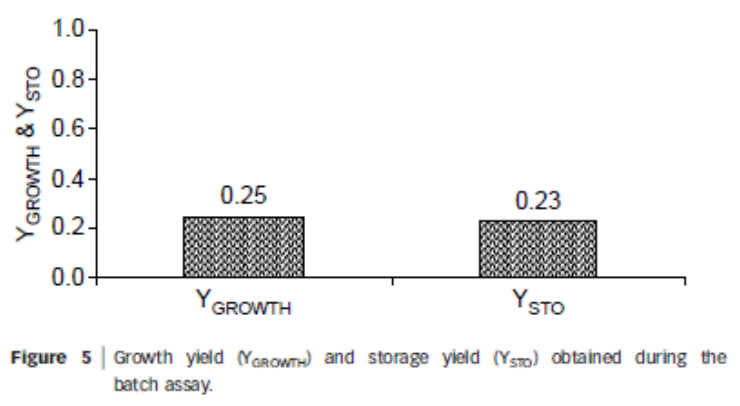

The main conclusions from this work are listed hereafter: Wood mill effluents were characterised by high organic matter and solids concentrations, low $\mathrm{pH}$ and nutrients limitation. Biodegradability of the raw wastewater was low, but it could be improved by filtering samples and/or increasing the reaction time.

Acidogenic fermentation of a wood mill effluent was carried out at $\mathrm{pH} 5.5,30^{\circ} \mathrm{C}$, OLR of $5.6 \mathrm{~g} \mathrm{COD/L} \mathrm{d} \mathrm{and} \mathrm{a} \mathrm{HRT} \mathrm{of} 1 \mathrm{~d}$. Reactor performance was stable during the first month of operation, obtaining an acidification percentage of $37 \%$, but $2 \mathrm{~g}$ $\mathrm{COD} / \mathrm{L}$ were still present in the treated effluent. Increasing HRT the acidogenesis could be improved, since there is a longer time to degrade this complex organic matter. Still, the possible presence of inhibitory compounds in the wastewater could affect the acidogenic step, being possible to reduce their concentrations by wastewater dilution.

An aerobic batch assay was performed using fermented wood mill effluent, in order to determine the feasibility of using this stream as a substrate for PHA production. The $\mathrm{Y}_{\text {STO }}$ obtained was $0.23 \mathrm{Cmmol} / \mathrm{Cmmol}$. This low value could be explained by the sludge acclimatisation with a different wastewater. Sludge was previously acclimated with fermented brewery wastewater, which contains very simple molecules (VFA and ethanol), while wood mill effluents are more complex. Sludge acclimation with fermented wood mill effluents could improve the process. Also the high initial ammonia concentration could affect the accumulation process. A one hour lag phase was observed in VFA consumption at the beginning of the assay, which could be related to a substrate inhibition. This could be due to the presence of complex organic matter, which was not degraded in the previous step.

\section{Acknowledgements}

The present research was financed by the Xunta de Galicia. (Project 08MDS027103PR). 


\section{References}

Albuquerque, M. G. E., Eiroa, M., Torres, C., Nunes, B. R. \& Reis, M. A. M. 2007. Strategies for the development of a side stream process for polyhydroxyalkanoates (PHA) production from sugar cane molasses. J. Biotechnol. 130,411 - 421.

Amat, A. M., Arques, A., Miranda, M. A. \& Lo' pez, F. 2005.Use of ozone and/or UV in the treatment of effluents from board paper industry. Chemosphere 60, 1111-1117.

APHA - AWWA - WPCF 1998 Standard Methods for the Examination of Water and Wastewater. 20th edition, Washington DC, USA.

Bengtsson, S., Hallquist, J., Werker, A. \& Welander, T. 2008a. Acidogenic fermentation of industrial wastewater: effects of chemostat retention time and $\mathrm{pH}$ on volatile fatty acids production. Biochem. Eng. J. 40, $492-499$.

Bengtsson, S., Werker, A., Christensson, M. \& Welander, T. 2008b. Production of polyhydroxyalkanoates by activated sludge treating a paper mill wastewater. Bioresour. Technol. 99, 509 - 516.

Braunegg, G., Sonnleitner, B. \& Lafferty, R. M. 1978. A rapid gas chromatographic method for the determination of poly-b- hydroxybutyric acid in microbial biomass. Eur. J. Appl. Microbiol. Biotechnol. 6, 29 - 37.

Comeau, Y., Hall, K. J. \& Oldham, W. K. 1988. Determination of poly-bhydroxybutyrate and poly-b-hydroxyvalerate in activated sludge by gas-liquid chromatography. Appl. Environ. Microbiol. 54(9), 2325 - 2327.

Lee, S. Y. 1996 Bacterial Polyhydroxyalkanoates. Biotechnol. Bioeng. 49, 1 - 14.

Satoh, H., Mino, T. \& Matsuo, T. 1992 Uptake of organic substrates and accumulation of polyhydroxyalkanoates linked with glycolysis of intracellular carbohydrates under anaerobic conditions in the biological excess phosphate removal processes. Water Sci. Technol. 29, $933-949$.

Serafim, L. S., Lemos, P. C., Oliveira, R. \& Reis, M. A. M. 2004. Optimization of polyhydroxybutyrate production by mixed cultures submitted to aerobic dynamic feeding conditions. Biotechnol. Bioeng. 87(2), 145 - 160.

Stuthridge, T., Gapes, D., McGrouther, K. \& Slade, A. 2009. Novel methods to convert pulp and paper waste streams into added value products. 7th International Conference on Fate and Effects of Pulp \& Paper Mill Effluents and 9th Symposium on Forest Industry Wastewaters, Canada.

Vidal, G. \& Diez, M. C. 2005 Methanogenic toxicity and continuous anaerobic treatment of wood processing effluents. J. Environ. Manage. 74, 317 - 325. 